\title{
Research on Capacitor Bank Failure Processing Methods
}

\author{
Tong Rui ${ }^{1}$, Liu Jiyong ${ }^{1}$, Wang Ning $^{2}$, Chen Ruiguo ${ }^{2}$, Wang Qinghao ${ }^{1}$, Pang Yanjun ${ }^{1}$, \\ Zhang Bo ${ }^{1}$, Su Hainan ${ }^{3}$, Yang Yue ${ }^{4}$, Wang Enlu ${ }^{1}$, Zhang Wenguang ${ }^{1}$, Liu Chuan ${ }^{1}$ \\ ${ }^{1}$ Fushun Power Supply Company, Liaoning Electric Power Company Limited, State Grid, China \\ ${ }^{2}$ Liaoning Electric Power Company Limited, State Grid, China \\ ${ }^{3}$ Dandong Power Supply Company, Liaoning Electric Power Company Limited, State Grid, China \\ ${ }^{4}$ Maintenance Branch, Liaoning Electric Power Company Limited, State Grid, China \\ fushunpowersupply@163.com
}

Keywords: tapped; discharge coil; unbalanced voltage; voltage ratio

\begin{abstract}
Aiming to the problem of running with the capacitor bank balance protection action causing tripping, by on-site analysis of the phenomenon and the capacitor discharge coil voltage ratio test checks, secondary coil voltage has relatively large errors caused by the tapped discharge coil. When the system voltage fluctuations, voltage unbalance will break through the setting value, causing balance protection action conclusions; proposed discharge coil tapped in the transfer test or tuning capacitor bank balance protection action value, the voltage ratio between whole primary and secondary should be checked of the discharge coil.
\end{abstract}

\section{Introduction}

Shunt capacitor compensation device commonly used in power systems, mainly to solve the system of reactive power compensation, improve system voltage. In the system during normal operation, capacitor bank voltage imbalance often happens, leading to tripping accidents. After examination, the compensation for damage caused an imbalance of the capacitor element, discharge coil secondary open delta voltage imbalance causing protection tripping. However, some shunt capacitor protection often unbalanced act, leading to switch trip, after examination failed to find the cause of the malfunction. If put into operation again, unexplained imbalance protection tripping will still happen[1-3].

\section{Fault overview and descriptions}

(1) Failure Overview

A $10 \mathrm{kV}$ substation capacitor bank \# 1 put into operation, after a period of time, often unbalanced protection action, switch trip, the time interval ranging from two months to a year, each capacitor routine tests were performed to check the fault, the test results normal, in this period also conducted several comprehensive preliminary examination interval capacitor device.

(2) Test inspection

Through discharge coil and reactor preliminary examination, the data has not found exception. Part of the experiment data is shown in Table 1 and 2.

Table 1 Reactor DC resistance test data

\begin{tabular}{|c|c|c|c|}
\hline Pilot project & A & B & C \\
\hline DC resistance $(\Omega)$ & 0.01032 & 0.01027 & 0.01021 \\
\hline
\end{tabular}

Tables 1 and 2 data show no abnormalities. Also capacitor switching interval, theology, cables, surge arresters and other equipment were examined, nor unusual. Protection of personnel protection equipment and protection action setting values were examined, also found no abnormalities. 
Table 2 Discharge coil voltage ratio test data

\begin{tabular}{|c|c|c|c|c|c|}
\hline \multirow{2}{*}{ Phase } & \multicolumn{2}{|c|}{ Primary voltage (V) } & \multicolumn{2}{c|}{ Secondary voltage (V) } & $\begin{array}{c}\text { Voltage referred to } \\
\text { secondary side (V) }\end{array}$ \\
\hline \multirow{2}{*}{$\mathrm{A}$} & $\mathrm{A}_{1} \mathrm{~A}_{2}$ & 130 & $\mathrm{a}_{1} \mathrm{x}_{1}$ & 4.067 & 99.345 \\
\cline { 2 - 6 } & $\mathrm{A}_{2} \mathrm{X}$ & 130 & $\mathrm{a}_{2} \mathrm{X}_{2}$ & 4.055 & 99.051 \\
\hline \multirow{2}{*}{$\mathrm{B}$} & $\mathrm{B}_{1} \mathrm{~B}_{2}$ & 130 & $\mathrm{~b}_{1} \mathrm{X}_{1}$ & 4.067 & 99.345 \\
\cline { 2 - 6 } & $\mathrm{B}_{2} \mathrm{X}$ & 130 & $\mathrm{~b}_{2} \mathrm{X}_{2}$ & 4.093 & 99.979 \\
\hline \multirow{2}{*}{$\mathrm{C}$} & $\mathrm{C}_{1} \mathrm{C}_{2}$ & 130 & $\mathrm{C}_{1} \mathrm{x}_{1}$ & 4.092 & 99.955 \\
\cline { 2 - 6 } & $\mathrm{C}_{2} \mathrm{X}$ & 130 & $\mathrm{C}_{2} \mathrm{x}_{2}$ & 4.078 & 99.613 \\
\hline
\end{tabular}

\section{Failure Analysis}

(1) Further tests to check

The frequent occurrence of capacitor bank unbalance protection action, indicating that there must be unable to identify the cause of the fault exists. Through the analysis of the data has been tested that capacitors without exception[4,5]. The discharge coil only measured once the tap corresponding to the secondary winding coil voltage ratio, in order to discharge coil comprehensive analysis, conducted a discharge coil primary winding as a whole than the test voltage of the secondary coil. Test data is shown in Table 3.

Table 3 Part of the discharge coil test data

\begin{tabular}{|c|c|c|c|c|c|}
\hline \multirow{2}{*}{ Phase } & \multicolumn{2}{|c|}{ Primary voltage $(\mathrm{V})$} & \multicolumn{2}{|c|}{ Secondary voltage (V) } & $\begin{array}{c}\text { Voltage referred to secondary } \\
\text { side }(\mathrm{V})\end{array}$ \\
\hline \multirow{2}{*}{$\mathrm{A}$} & \multirow{2}{*}{$\mathrm{A}_{1} \mathrm{X}$} & \multirow{2}{*}{260} & $\mathrm{a}_{1} \mathrm{x}_{1}$ & 3.965 & 96.853 \\
\cline { 4 - 6 } & & $\mathrm{a}_{2} \mathrm{x}_{2}$ & 4.186 & 102.25 \\
\hline \multirow{2}{*}{$\mathrm{B}$} & \multirow{2}{*}{$\mathrm{B}_{1} \mathrm{X}$} & \multirow{2}{*}{260} & $\mathrm{~b}_{1} \mathrm{x}_{1}$ & 4.200 & 102.59 \\
\cline { 4 - 6 } & & $\mathrm{b}_{2} \mathrm{x}_{2}$ & 3.956 & 96.631 \\
\hline \multirow{2}{*}{$\mathrm{C}$} & \multirow{2}{*}{$\mathrm{C}_{1} \mathrm{X}$} & \multirow{2}{*}{260} & $\mathrm{c}_{1} \mathrm{x}_{1}$ & 3.908 & 95.460 \\
\cline { 4 - 6 } & & $\mathrm{c}_{2} \mathrm{x}_{2}$ & 4.258 & 104.01 \\
\hline
\end{tabular}

(2) Data Analysis

As can be seen by the data in Table 4, there is a large imbalance voltage between the secondary winding of each group of the discharge coil. Discharge coil secondary winding first phase connected with each other (a1x1-b1x1-c1 1 1 and a2x2-b2x2-c2x2) to form a opening triangular, the voltage difference constitutes the unbalanced voltage. Since each set of the secondary coil voltage has a big difference, leads to a relatively large opening triangular occurs unbalance voltage, which is formed of the vector diagram shown in Figure 1 and Figure 2.

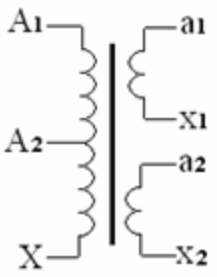

(A phase)

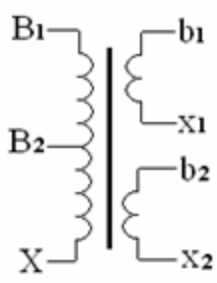

(B phase)

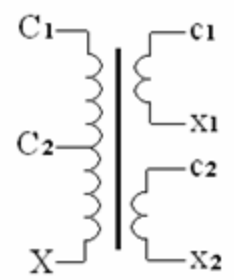

(C phase)

Figure 1 Triangular openings unbalanced voltage $\Delta \mathrm{U}$ 


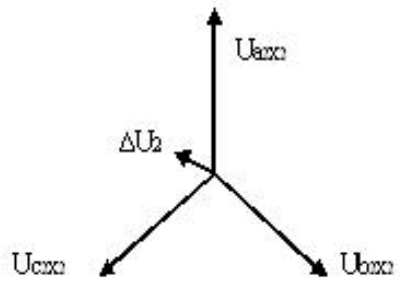

Figure 2 Opening triangular voltage imbalance $\Delta \mathrm{U}_{2}$

By calculation, we can draw two open delta voltage Figure 3 and Figure 4, respectively $\Delta \mathrm{U}_{1}=$ $6.594 \mathrm{~V}$ and $\Delta \mathrm{U}_{2}=6.676 \mathrm{~V}$ under (assuming ideal conditions, the three-phase primary winding voltage are $11 / \mathrm{kV}$, respectively, the phase angle difference $120^{\circ}$ ), and this unbalanced voltage capacitor bank protection action setting is $5.86 \mathrm{~V}$. As the actual grid voltage applied across the coil discharge is generally less than $11 / \mathrm{kV}$ and the presence of the measuring error, and the above analysis result data is idealized, so during normal operation, the actual open delta voltage may be in protected from critical point balance voltage operation around the set value, when the system voltage fluctuations, voltage unbalance will break through the setting value, causing tripping protection.

\section{Fault handling}

After identify the reason, replace the discharge coil. Put into operation before the handover of the discharge coil test, simultaneous measurement of the primary winding and a secondary winding of the overall center-tapped secondary winding coil voltage ratio, the experimental data are shown in Table 4.

Table 4 Discharge coil voltage ratio test data

\begin{tabular}{|c|c|c|c|c|c|}
\hline Phase & \multicolumn{2}{|c|}{ Primary voltage $(\mathrm{V})$} & \multicolumn{2}{|c|}{ Secondary voltage $(\mathrm{V})$} & $\begin{array}{l}\text { Voltage referred to secondary } \\
\text { side }(\mathrm{V})\end{array}$ \\
\hline \multirow{4}{*}{ A } & \multirow{2}{*}{$\mathrm{A}_{1} \mathrm{X}$} & \multirow{2}{*}{260} & $\mathrm{a}_{1} \mathrm{x}_{1}$ & 4.135 & 101.01 \\
\hline & & & $\mathrm{a}_{2} \mathrm{x}_{2}$ & 4.036 & 98.587 \\
\hline & $\mathrm{A}_{1} \mathrm{~A}_{2}$ & 130 & $\mathrm{a}_{1} \mathrm{x}_{1}$ & 4.077 & 99.589 \\
\hline & $\mathrm{A}_{2} \mathrm{X}$ & 130 & $\mathrm{a}_{2} \mathrm{x}_{2}$ & 4.063 & 99.247 \\
\hline \multirow{4}{*}{ B } & \multirow{2}{*}{$\mathrm{B}_{1} \mathrm{X}$} & \multirow{2}{*}{260} & $\mathrm{~b}_{1} \mathrm{x}_{1}$ & 4.107 & 100.32 \\
\hline & & & $\mathrm{b}_{2} \mathrm{x}_{2}$ & 4.062 & 99.223 \\
\hline & $\mathrm{B}_{1} \mathrm{~B}_{2}$ & 130 & $\mathrm{~b}_{1} \mathrm{x}_{1}$ & 4.066 & 99.320 \\
\hline & $\mathrm{B}_{2} \mathrm{X}$ & 130 & $\mathrm{~b}_{2} \mathrm{x}_{2}$ & 4.068 & 99.369 \\
\hline \multirow{4}{*}{$\mathrm{C}$} & \multirow{2}{*}{$\mathrm{C}_{1} \mathrm{X}$} & \multirow{2}{*}{260} & $\mathrm{c}_{1} \mathrm{x}_{1}$ & 4.143 & 101.20 \\
\hline & & & $\mathrm{C}_{2} \mathrm{x}_{2}$ & 4.031 & 98.465 \\
\hline & $\mathrm{C}_{1} \mathrm{C}_{2}$ & 130 & $\mathrm{c}_{1} \mathrm{x}_{1}$ & 4.081 & 99.687 \\
\hline & $\mathrm{C}_{2} \mathrm{X}$ & 130 & $\mathrm{C}_{2} \mathrm{X}_{2}$ & 4.069 & 99.393 \\
\hline
\end{tabular}

As can be seen from the data in Table 5, both the primary coil to the secondary coil as a whole, or an intermediate tap of the primary coil voltage phase difference than the secondary coil is not very big, does not appear the large open delta voltage under normal operating voltage, resulting in unbalanced voltage protection action and switch trip.

\section{Conclusion}

The tapped type discharge coil in the handover test should be measured at the same time discharge coil a whole of two secondary coils and a coil tap voltage on the two secondary coil ratio. 
If the operation process, found the capacitor bank protection of unbalanced voltage action, conventional tests check without exception, should first consider checking the voltage ratio between the primary and the secondary of the discharge coil. Fault analysis and treatment method of the case; also apply to the discharge coil without tap voltage ratio check.

\section{References}

[1] Zhang Longcai,Jiang Xipei,You Chuanyong. Status and prospects of new composite materials composite core wire. China Electric Power Press, 2005.

[2] You Chuanyong. A Comparative Study of overhead transmission line conductors Capacity [J]. Power construction, 2007.

[3] Zhao Zuoli,Wang Li,Jiang Zhenfu. Carbon fiber composite core aluminum wire used in the transformation of the grid lines in Liaoning [J]. Power construction, 2007.

[4] Zhang Rui,Wu Yaguang. Development and Prospect of China's key manufacturing technology of composite insulators [J]. High Voltage Technology, 2007.

[5] Ding Jingling. Research Rod Composite Insulator Metal accessory connection zone mechanical properties [J]. Porcelain arrester, 2006. 